\section{Dinâmica familiar de criança com a síndrome congênita do Zika vírus no Município de Petrolina, Pernambuco, Brasil}

\author{
Family dynamics of children with congenital Zika \\ syndrome in Petrolina, Pernambuco State, Brazil \\ Dinámica familiar de niños afectados por el \\ síndrome congénito del virus Zika, municipio \\ de Petrolina, Pernambuco, Brasil
}

\section{Resumo}

No Brasil, houve aumento no número de casos de microcefalia detectados em crianças nascidas no segundo semestre de 2015. Esses casos tiveram incremento significativo no país. Em 2014, foram 162 ocorrências, aumentando, em 2015, para 1.608. Essa condição está associada a vários acometimentos nas funções do organismo, levando a limitações no desenvolvimento infantil. Esta pesquisa objetiva analisar a dinâmica familiar de criança com a síndrome congênita associada ao Zika vírus (SCZV) no Municipio de Petrolina, Pernambuco. Como instrumento de coleta, utilizou-se a consulta ao prontuário e a realização de entrevista por meio de roteiro semiestruturado. Empregou-se abordagem quali-quantitativa, envolvendo a totalidade das mães e dos familiares que acompanhavam as crianças com a SCZV na unidade de saúde de referência, AME Amália Granja Alencar. Na análise dos discursos, aplicou-se a técnica de análise de conteúdo. Os resultados relacionados à categoria mudanças da vida diária de familiares de criança com a SCZV foram agrupados em três subcategorias: atividade da vida diária (AVD); impactos financeiros e no trabalho associados à descoberta da SCZV; e mudança na relação conjugal após a descoberta da SCZV. A pesquisa demonstrou majoritariamente que o cuidado da criança com SCZV está centrado na figura feminina e que o diagnóstico traz significativas mudanças na dinâmica familiar, como maior dependência da criança ao cuidador, aumento de gastos financeiros e absenteísmo no trabalho.

Microcefalia; Criança com Deficiência; Centros de Saúde; Zika Vírus; Relações Familiares
Simone Aline Araújo Guimarães de Sá 1

Claudia Cavalcanti Galindo 1

Regina Santos Dantas 1

José Carlos de Moura 1

doi: 10.1590/0102-311X00246518

\section{Correspondência}

S. A. A. G. Sá

Rua Los Ângeles 81, Petrolina, PE 56328-615, Brasil.

simonealinearaujo@hotmail.com

1 Universidade Federal do Vale do São Francisco, Petrolina, Brasil. 


\section{Introdução}

Em 2015, houve incremento inesperado de casos de microcefalia no Brasil, especialmente na Região Nordeste 1,2. Inicialmente, Pernambuco era o estado com maior número de registros; foram contabilizados, nesse estado, entre 2015 e 2017, um acumulado de 436 casos confirmados de síndrome congênita associada ao Zika vírus (SCZV) 3 .

Por isso, o Ministério da Saúde normatizou em 2015 parâmetros para investigação de casos suspeitos de microcefalia nos recém-nascidos; considerou-se diminuição do perímetro cefálico (PC) menor que dois desvios padrão. Assim, para recém-nascidos a termo era considerado como caso suspeito, PC menor que $32 \mathrm{~cm} 4$.

Em 2016, os parâmetros foram reduzidos, sendo padronizada a tabela da Organização Mundial da Saúde (OMS) para os recém-nascidos a termo. Com isso, consideraram-se como casos suspeitos de microcefalia os valores de PC menor que $31,9 \mathrm{~cm}$ para meninos e menor que $31,5 \mathrm{~cm}$ para meninas. Posteriormente, conforme recomendação da OMS, utilizou-se o padrão internacional da tabela InterGrowth para os recém-nascidos prematuros, segundo a curva de acompanhamento dividida por categoria sexo e idade gestacional. Portanto, para uma criança nascida com 37 semanas, com medição até 48 horas de vida, o valor do PC de corte é $30,24 \mathrm{~cm}$ para meninas e 30,54cm para meninos 4,5 .

Compreende-se a microcefalia como um sinal de alteração na formação do cérebro 5,6. Essas alterações neurológicas dependem da influência de fatores relacionados à infecção congênita como: carga viral; fatores intrínsecos do hospedeiro; acometimento da infecção, a exemplo do período gestacional ou outras situações ainda não estudadas $3,4,6,7,8$.

Dentre as diversas causas da microcefalia, encontram-se os agentes infecciosos reconhecidos de transmissão vertical com consequências no desenvolvimento neurológico como: citomegalovírus, toxoplasmose, rubéola, herpes viral e vírus Zika (ZIKV) 4,8,9.

Sabe-se que existe situação de criança com PC dentro do esperado para idade e sexo, no entanto apresenta também alteração no desenvolvimento cerebral ${ }^{4}$. Diante disso, foi proposta nova nomenclatura "síndrome congênita associada ao Zika vírus" abrangendo a microcefalia e o conjunto de alterações neurológicas 4,7 .

A vinda de uma criança com deficiência pode provocar alterações na família com mistura de sentimentos e interações, em que um altera e sofre alterações na relação com o outro dentro do núcleo familiar a partir do seu nascimento, provocando mudanças na organização da família 10. Entende-se que o amadurecimento da família e a maneira como os pais enfrentam a deficiência estão relacionados com as aptidões presentes na família e na rede de apoio disponível 11.

Flamengui Jr. \& Messa 12 utilizam uma adaptação do estudo sobre as fases de transformação comuns em uma família, proposto para as etapas de vida da família de crianças com deficiência, numa sequência de oito fases, envolvendo desde o período de "casais recém-casados" a "familiares de idosos". Acresce que, além das crises comumente encontradas nas famílias de crianças com comportamento típico, as famílias de crianças com deficiência têm ainda o fator de adaptação à situação de deficiência, assim vivenciam tais etapas com as variações de particularidades e comprometimentos de cada caso com as possíveis repercussões no desenvolvimento familiar.

Por conta disso, as adaptações na rotina familiar, comumente exigidas com a chegada de uma criança com prováveis comprometimentos no desenvolvimento infantil, associados ao aumento de demandas diárias que os cuidadores dedicam a essas crianças, podem disparar conflitos entre os relacionamentos familiares, pois a chegada da criança com deficiência, por vezes, ocasiona mudanças em planos e perspectivas devido ao novo contexto familiar 13.

Tendo em vista a situação de incidência de SCZV no Estado de Pernambuco, aliada à necessidade de informações sobre as mudanças provocadas nos familiares cuidadores das crianças com SCZV no Município de Petrolina, esta pesquisa tem o objetivo de analisar a dinâmica familiar de criança com a SCZV, no Município de Petrolina. 


\section{Métodos}

Este estudo segue as diretrizes e normas que regulamentam as pesquisas envolvendo seres humanos, contidos na Resolução no 466/2012 14, submetido e aprovado na apreciação do Comitê de Ética e Deontologia em Estudos e Pesquisas (CEDEP) da Universidade Federal do Vale do São Francisco (UNIVASF), sob parecer número 1.718.310.

Trata-se de estudo descritivo e exploratório e de abordagem qualitativa. O método qualitativo compreende um processo mais intuitivo e maleável, capaz de se adaptar a índices não previstos, ou à evolução das hipóteses 15. Portanto, esse tipo de abordagem tem como objeto da pesquisa os fenômenos apreendidos na "interpretação das relações de significado dos fenômenos, como referidos pelas pessoas" 16 (p. 511).

O estudo foi desenvolvido no Município de Petrolina. Segundo o Instituto Brasileiro de Geografia e Estatística (https://cidades.ibge.gov.br/, acessado em 21/Nov/2017), essa cidade possui estimativa de 343.219 habitantes; faz divisa com a cidade de Juazeiro, no Estado da Bahia, compondo, junto a outros 53 municípios, a Rede Interestadual de Atenção à Saúde do Vale do Médio São Francisco (Rede PEBA) 17.

A unidade básica de saúde (UBS), Atendimento Multiprofissional Especializado (AME) - Amália Granja Alencar, foi escolhida como campo de estudo porque foi destinada a prestar apoio na assistência multiprofissional às crianças diagnosticadas com microcefalia associada ao ZIKV e residentes no município, desenvolvendo, concomitantemente, ações do Programa de Estimulação Precoce, por meio da equipe multidisciplinar do Núcleo Ampliado de Saúde da Família (NASF), composta por psicólogo, fisioterapeuta, nutricionista, terapeuta ocupacional, fonoaudiólogo e pediatra 18 .

A pesquisa foi desenvolvida durante o período de fevereiro de 2015 a dezembro de 2017, sendo a coleta de dados no período entre setembro de 2016 e abril de 2017. A população foi composta por nove mães e cinco familiares compreendendo a totalidade das mães e dos familiares cuidadores de crianças com SCZV do Município de Petrolina e acompanhadas no Sistema Único de Saúde (SUS) por equipe multiprofissional na AME Amália Granja Alencar, referência na "estimulação precoce" nessas crianças no município.

As entrevistas realizadas com as mães e familiares foram direcionadas por questões que abordavam percepções sobre as mudanças na rotina da família após o diagnóstico de microcefalia e aspectos sobre o trabalho, gastos financeiros e relação conjugal.

Posteriormente, foi apresentada a proposta de estudo, critérios e etapas, ao grupo de familiares constituídos na referida unidade de saúde. Após a apresentação, foram convidados a participar da pesquisa, sendo esclarecido o direito de recusa e de desistência em qualquer etapa do estudo sem qualquer prejuízo ao familiar ou à criança. Contemplou-se também a apresentação do Termo de Consentimento Livre e Esclarecido e o Termo de Sigilo e Confidencialidade.

Após assinatura dos referidos termos, iniciou-se a entrevista dos participantes. A princípio, foi realizada a aplicação de um piloto do roteiro de entrevista a uma parcela da população, para fins de ajustes do tempo da entrevista e aperfeiçoamento do instrumento.

As entrevistas foram previamente agendadas com a totalidade das mães e familiares das crianças assistidas na unidade de saúde de referência, realizadas de maneira individualizada, utilizando roteiro semiestruturado, sendo encerradas após exploração das questões e respeitando tempo de cada entrevistado, em momento único, em sala disponibilizada pela UBS.

Foram compostos dois grupos de entrevista: genitoras das crianças com SCZV e familiares que acompanhavam as crianças na assistência. As entrevistas foram áudio-gravadas para posterior consulta e foram transcritas na íntegra.

Dentre os critérios de inclusão, encontram-se: possuir laudo de neuropediatra confirmando a microcefalia associada ao ZIKV e realizar acompanhamento no SUS. Foram descartados da coleta de dados, familiares de crianças que não residiam no Município de Petrolina.

Os resultados foram agrupados pela caracterização da população, e, em relação aos impactos psicossociais, foi reunido em uma categoria. Para o sigilo dos participantes, usou-se a identificação mãe ou familiar, seguido de sigla e sequência numérica das crianças (CR) da pesquisa.

Segundo Minayo 19, a análise tem por objetivo permitir melhor entendimento das informações coletadas, contribuindo para o enriquecimento dos conhecimentos acerca do assunto pesquisado. 
Para a análise do material obtido nas entrevistas, utilizou-se a Análise de Conteúdo proposta por Bardin 15, que a descreve como método que permite identificar os principais elementos no discurso de um determinado grupo e as suas significações. Os dados adquiridos na entrevista, depois, foram agrupados em categorias e analisados. Tal técnica consiste em três etapas: a pré-análise; a exploração do material; e o tratamento dos resultados, realizando uma inferência e uma interpretação dos dados.

A pré-análise corresponde à organização de todo material que será utilizado para a coleta dos dados, ou que possa ajudar a compreender melhor o fenômeno e fixar a especificação do campo em que o pesquisador deve centrar a atenção, o chamado corpus da investigação.

Ainda para a fase de pré-análise, o pesquisador colaborador obedeceu às seguintes regras para a escolha dos documentos, essenciais para a garantia da sua eficácia: Exaustividade - deve-se esgotar a totalidade da comunicação, não omitir nada; Representatividade - a amostra deve representar o universo; Homogeneidade - os dados devem se referir ao mesmo tema, ser obtidos por técnicas iguais e colhidos por indivíduos semelhantes; e Pertinência - os documentos precisam se adaptar ao conteúdo de modo a corresponder ao objetivo da pesquisa.

É pela análise que surgem conjuntos de referência, procurando sínteses coincidentes e divergentes de ideias. Desse modo, de acordo com Silva et al. 20, o pesquisador não deve restringir sua análise ao conteúdo, e deve ocorrer interação dos materiais colhidos. Dessa forma, as ideias e fundamentos empíricos do material estabeleceram relações com a realidade, aprofundando as conexões das opiniões.

No que tange à análise e interpretação das respostas associadas às opiniões que emergiram nas entrevistas, foi estabelecido uma relação entre os dados categorizados com o referencial teórico analisado, identificando as divergências e convergências enunciadas pelos entrevistados deste estudo.

\section{Resultados e discussões}

No Quadro 1, pode-se observar o perfil dos entrevistados.

Carneiro 21 destaca a importância de mudança no pensar diante da situação de Zika no país, em razão da complexidade que a situação da epidemia requer. Sugere que se tracem mapas abrangentes sobre as regiões mais acometidas de forma a contemplar aspectos sociais dos indivíduos acometidos, como também perfil contemplando idade, sexo, conjugalidade dentre outros fatores que possam esclarecer melhor a população atingida pelo ZIKV.

Em relação à mãe da criança com SCZV, destaca-se a predominância de mães jovens: 44\% encontravam-se na faixa etária de 20 a 24 anos, sendo a idade mínima encontrada de 19 anos e a máxima, 34 anos. Foi encontrado um perfil semelhante em estudo envolvendo crianças com microcefalia no Brasil entre os anos de 2000 a 2015, realizado por Marinho et al. 22, em que a maior prevalência se verificava entre mães menores de 24 anos e acima de 40 anos de idade. Assim também, observa-se na população estudada que a média de idade dos familiares entrevistados foi de 34 anos, com o mínimo de 26 anos e máximo de 50 anos.

No tocante à escolaridade das mães de crianças com SCZV, 100\% possuíam de 5 a 11 anos de estudo. Observa-se perfil semelhante no Brasil 22, onde a maioria das mães também não possui curso superior (87\%), com no máximo 11 anos de estudo, constatando uma maior prevalência da SCZV entre as mães com menor escolaridade. Entre os familiares, nota-se similarmente uma menor escolaridade: $25 \%$ possuem 11 anos de estudo e $75 \%$ possuem entre 4 e 10 anos de estudo.

No que se refere ao gênero do cuidador da criança, o estudo mostrou que $78 \%$ era do gênero feminino, demonstrando majoritariamente que recai sobre as mulheres os cuidados com os filhos, em especial os com necessidades especiais. Tal situação vivenciada pela mulher é descrita em diversos outros estudos, como consequência da posição de gênero imputada à mulher na sociedade, que assume os cuidados dos filhos e das tarefas domésticas 23,24. Em sua pesquisa, Silva (2014, apud Scott et al. 23) reforça o discurso de que a mulher é socialmente cobrada para o cuidado com os filhos, e tal fato é agudizado quando se trata de crianças com deficiência.

Referentemente ao estado civil das mães de crianças com SCZV, foi observado que a maioria declarou possuir companheiro: 55,55\% informaram que tinham relação estável ou eram casadas e 44,44\% sem companheiro, declararam-se separadas/solteiras. 


\section{Quadro 1}

Caracterização dos participantes da pesquisa que acompanhavam as crianças (CR) com síndrome congênita associada ao Zika vírus (SCZV) no programa de estimulação precoce do Município de Petrolina, Pernambuco, Brasil, no período de setembro de 2016 a abril de 2017.

\begin{tabular}{|c|c|c|c|c|c|}
\hline Entrevistado/a & $\begin{array}{c}\text { Parentesco com a } \\
\text { criança }\end{array}$ & Idade & Escolaridade & Sexo & Situação conjugal \\
\hline Mãe da CR001 & Mãe & 22 anos & 2o grau & Feminino & Separada \\
\hline Mãe da CR002 & Mãe & 34 anos & 10 grau & Feminino & Relação estável \\
\hline Mãe da CR003 & Mãe & 29 anos & 1ㅇ grau & Feminino & Casada \\
\hline Mãe da CR004 & Mãe & 29 anos & 2o grau & Feminino & Casada \\
\hline Mãe da CR005 & Mãe & 30 anos & 2oo grau incompleto & Feminino & Casada \\
\hline Mãe da CR006 & Mãe & 19 anos & 1ㅇ grau incompleto & Feminino & Relação estável \\
\hline Mãe da CR007 & Mãe & 20 anos & 10 grau incompleto & Feminino & Solteira \\
\hline Mãe da CR008 & Mãe & 20 anos & 2o grau incompleto & Feminino & Separada \\
\hline Mãe da CR009 & Mãe & 22 anos & 2o grau & Feminino & Separada \\
\hline Familiar da CR002 & Pai & 37 anos & 2o grau & Masculino & Relação estável \\
\hline Familiar da CR003 & Pai & 30 anos & 1o grau incompleto & Masculino & Casado \\
\hline Familiar da CR004 & Pai & 29 anos & 1o grau incompleto & Masculino & Casado \\
\hline Familiar da CR006 & Pai & 26 anos & 1o grau incompleto & Masculino & Relação estável \\
\hline Familiar da CR008 & Avó & 50 anos & 1ㅇ grau incompleto & Feminino & Separada \\
\hline
\end{tabular}

Fonte: dados da pesquisa (2017).

Embora em menor porcentagem, a situação declarada sem companheiro destaca-se pelo impacto social que pode provocar na rotina dessas cuidadoras, já que retrata a situação das genitoras que possuem menor apoio social no domicílio, tendo que exercer a função de pai e mãe dessas crianças. Fato descrito por Diniz 25, que cita a separação conjugal de mãe de criança com SCZV após recebimento do diagnóstico.

Conforme as informações dos participantes, agruparam-se a categoria que engloba a percepção sobre a dinâmica familiar, na tentativa de elucidar os aspectos contidos no cotidiano das famílias de crianças com SCZV, elencando as atividades diárias e o maior dispêndio financeiro em relação à criança.

De acordo com os discursos, agrupou-se na categoria: mudanças da vida diária de familiares de criança com a SCZV, e levantaram-se três aspectos que foram descritos em subcategorias e discutidos a seguir: atividade da vida diária (AVD), impactos financeiros e no trabalho associados a descoberta da SCZV e mudança na relação conjugal após a descoberta da SCZV.

\section{Categoria: mudanças da vida diária de familiares de criança com SCZV}

\section{- Subcategoria: atividade da vida diária}

Nessa subcategoria, descreve-se sobre aspectos da AVD relacionadas ao tempo, fatores que facilitam e que dificultam a realização dos cuidados à criança com SCZV. Os trechos do discurso descrevem quanto à permanência dessa criança no colo, como se observa:

"Passei [ontem] o dia todinho com ele no braço, que ele não quis dormir de jeito nenhum..." (mãe da CR007).

“...Ele era muito irritadiço, ele era, chorava muito... eu ficava vinte e quatro horas com ele no braço, até de madrugada, nem dormia...” (mãe da CR009).

Essa atitude de consolar a criança no colo foi descrita por todas as mães nos momentos de maior irritabilidade que provoca choro persistente nas crianças, especialmente encontrada nos primeiros 
meses de vida. Está descrito na literatura a irritabilidade como uma característica habitualmente identificada entre as crianças com SCZV 26.

Dessa maneira, está presente nos discursos a maior dependência da criança à mãe, ocasionando sobrecarga no desenvolvimento das AVD. Corroborando com estudo de Silva \& Dessen 10, com familiares de crianças com deficiência mental, a autora discorre sobre essa maior demanda para a mãe de crianças com deficiência, sobretudo nos cuidados cotidianos. Assim também, em outro estudo realizado por Silva \& Dessen 13, existiam poucas descrições entre crianças com deficiência intelectual e mães de crianças com deficiência física quanto à participação paterna na divisão de tarefas domésticas/cuidado dos filhos.

Entre os fatores que facilitam no cuidado às crianças, estão presentes nos discursos a espiritualidade materna e a presença de rede social de apoio, como se pode perceber nos segmentos dos discursos:

“...Acho que é Deus [risos] ...Eu adiciono muitas mães que têm microcefalia no Facebook... minha família me ajuda..." (mãe da CR009).

"Minha mãe me ajuda muito [risos]. Ajuda, minha mãe ajuda demais" (mãe da CR008).

A rede de apoio social é destacada em trechos de discursos de mães de crianças com SCZV. É essencial ressaltar a importância dessa rede como fator de proteção que influencia no cuidado ao filho com SCZV. Isso contribui no momento de enfrentamento de situações de crise, pois as informações sobre a deficiência e a presença efetiva de membros da família auxiliam na execução das AVD com as crianças. Juliano \& Yunes 27 (p. 141) descrevem que, nessas circunstâncias, “...não é apenas a família que deve ser levada em conta, pois os recursos dos diferentes contextos associados ao sistema familiar é que poderão compor 'forças ou fraquezas' que afetarão a adaptação do indivíduo, podendo aumentar ou diminuir o impacto de fatores de risco".

Os familiares abordam, entre as dificuldades enfrentadas nos cuidados diários às crianças, os aspectos motores e a tonicidade/espasmos musculares das crianças com SCZV, além da questão do transporte para realizar a assistência à criança.

Como afirmam Silva \& Dessen 10, cada família vai enfrentar adaptação a essa nova situação de acordo com as habilidades e características individuais. Flamenghi Jr. \& Messa 12 citam, em estudo com familiares de crianças com "deficiência mental", que diversos fatores estão implicados na adaptação dos membros da família e em "maior resiliência”. Alguns deles são o tamanho da família e o melhor rendimento financeiro.

Percebe-se, então, no discurso da mãe da CR001, o uso das habilidades disponíveis para contornar a situação de cuidar sozinha da criança com deficiência. Aspectos relacionados ao déficit da autonomia da criança aparecem nos discursos do familiar da CR002 e da mãe da CR007, que abordam sobre a dependência da criança e sobrecarga de atividades para a mãe, em consequência do maior tempo exigido em que a criança fica no colo.

“...Eu estar só, tá fazendo o papel de mãe e de pai dele né (...) às vezes eu coloco ele no carrinho mas ele fica chorando..." (mãe da CR001).

“...A gente não pode sair de perto dele nem um segundo que ele ainda num senta, entendeu?” (familiar da CR002).

"...Porque ele só fica quieto no meu braço. Se eu der ele a outra pessoa, ele fica... aí... se ele sentir minha falta, ai ele fica chorando, chorando, até eu pegar ele. Aí eu boto ele no braço e ele fica calado" (mãe da CR007).

Estudo realizado por Pereira-Silva et al. (2012, apud Silva \& Dessen 13) relata a diferença entre pais de crianças com síndrome de Down e de crianças com comportamento típico, demonstrando que o cuidado de crianças com deficiência intelectual obriga mais esforço, ocasionando maior sobrecarga do que em pais com filhos de comportamento típico. Essa sobrecarga, experienciada entre os pais de crianças com deficiência mental, torna-se um fator de risco para o aparecimento do estresse.

Na pesquisa, a mãe da CR005 cita como dificuldade do cuidado diário à criança a situação de tosse e engasgo, que indica comprometimento do desenvolvimento motor da deglutição: “...é mais em braço, porque às vezes ele também tosse, se engasga, ai eu fico com medo... Aí eu sei que com essa idade de nove meses já não sustenta tanto [leite materno], então pra mim a dificuldade é essa, de ele não se habituar a comer direitinho que nem os outros bebês...”.

Os problemas de deglutição são comuns em crianças com alterações neurológicas, citados por vários autores na atenção à saúde voltada para a alimentação 28. 
O aparecimento de problemas na musculatura orofacial, que ocasiona dificuldades na deglutição, é considerado frequente em crianças com comprometimento neurológico, entre as quais as crianças com microcefalia. Portanto, uma parcela das crianças com SCZV apresenta dificuldades de deglutição, com risco de broncoaspiração e, consequentemente, maior predisposição à pneumonia, dificuldade em manter peso adequado para a idade, além de desnutrição e desidratação 28,29 .

\section{- Subcategoria: impactos financeiros e no trabalho associados à descoberta da SCZV}

Dentre as mudanças enfrentadas pelas famílias de crianças com SCZV, encontra-se o aumento nos gastos financeiros. Percebe-se nos discursos que, na maioria dos casos, esse incremento está relacionado com demandas para um melhor desenvolvimento da criança, como a aquisição de medicamentos e brinquedos, bem como moradia, transporte e alimentação. Além disso, houve influência nas atividades desenvolvidas no trabalho após diagnóstico da SCZV. Os discursos abordam gastos financeiros em relação à presença da síndrome devido às peculiaridades da deficiência, como se nota na fala do familiar da CR006: "Aumenta muito. Transporte, mudou bem, remédio pra ele... tudo gasta mais (...) quatrocentos reais a mais. ...porque eu trabalho de diária por fora. Só o que nós ganha num dá não. Tem que se virar".

Nesse sentido, o estudo realizado por Vernier \& Cabral 30, com famílias de crianças com necessidades especiais de saúde, corrobora com o achado de aumento de gastos financeiros, uma vez que encontrou também que, na maioria das famílias, o custeio do transporte é realizado com recursos próprios durante a procura pela assistência às crianças, sendo avaliado pelas famílias como de maior impacto no orçamento financeiro.

Além disso, está presente no discurso das genitoras entrevistadas que residem em casas de aluguel, situações consideradas negativas que envolvem: saída do trabalho, mudança da situação de moradia e de município, por conta da busca de melhor assistência para a criança com SCZV.

"Houve. Tive que vir embora, porque eu morava na roça. (...) Ai eu tive que vir pra cá porque lá não tinha todos os tratamentos dela, e tive que trazer ela pra cá. Foi uma mudança e... muita..." (mãe da CR008).

"...A questão do aluguel mesmo né, que antes eu morava no trabalho ou se não com meus pais né (...) tive que sair do trabalho..." (mãe da CR002).

Também se conferem aspectos positivos em relação à área social com a concessão de moradia em programas sociais do estado. Conforme se observa no fragmento do trecho do discurso da mãe da CR003: “...porque através de [nome da criança], ganhei agora a casa, Minha Casa Minha Vida, ganhei por conta dela...”.

Embora algumas famílias ainda não tenham obtido essa concessão, buscam alcançar esse benefício porque se encontram em situação de moradia alugada: "Habitação, né. Porque seria também uma ajuda assim, se eu conseguisse a Minha Casa, Minha Vida, ter a minha própria casa, (...) tô procurando bastante a secretaria" (mãe da CR008).

Observa-se nos trechos do discurso sobre o recebimento do benefício o impacto financeiro nas AVD: "Conseguir o benefício dele né, ia ajudar bastante, serve pra comprar o remédio dele (...) melhora pra ele" (familiar da CR009).

"...Tudo depende de dinheiro, eu queria um salário mais digno pra mim poder comprar brinquedos mais estimulativos (...) poder ter uma pessoa do meu lado também pra me ajudar..." (mãe da CR002).

As famílias consideram importantes algumas demandas relacionadas aos aspectos financeiros que poderiam contribuir para melhor desenvolvimento da criança como: a concessão do Benefício de Prestação Continuada (BPC) para medicamentos e a aquisição de brinquedos que atuam na estimulação sensorial e motora das crianças. Especialmente nas famílias que não são beneficiárias de ajuda financeira do Estado, são citados fatores financeiros que dificultam o cotidiano delas com suas crianças como relata familiar da CR009, que tem que buscar incremento na renda para suprir as necessidades mínimas da criança. A ausência do apoio efetivo da rede social, seja por parte de instituições estatais ou da impossibilidade de apoio da rede familiar, apresentam-se como fatores que dificultam no cuidado diário à criança também presente no discurso da mãe da CR002.

Os trechos dos discursos evidenciam maior demanda com a criança, particularmente com assistência à saúde. Percebeu-se que é recorrente a interferência no trabalho, seja com atrasos, absenteísmo ou mesmo fazendo a opção de parar de trabalhar enquanto as crianças são pequenas, sendo o último 
comportamento percebido entre as mães. E também se encontram nas falas a descontinuidade dos estudos e a mudança nos projetos futuros por causa da maior dependência da criança com SCZV.

“...Pretendia trabalhar e fazer minha faculdade (...) Mas aí [nome do filho] mudou minha vida completamente [risos]” (mãe da CR001).

“...Eu perco muito dia [de trabalho] pra vir com ele pro hospital, que muitas vezes ela não pode...” (familiar da CR006).

Estudos sobre famílias de crianças com síndrome de Down demonstram que os pais apresentam maior sobrecarga no desenvolvimento de atividades cotidianas do que as vivenciadas por genitores de crianças com comportamento típico 13 .

\section{- Subcategoria: mudança na relação conjugal após a descoberta da SCZV}

Verifica-se na pesquisa que a presença de uma criança com deficiência não é fator determinante na crise conjugal, porém características individuais do casal são ressaltadas com a vinda de uma criança, sobretudo com SCZV e suas necessidades, fato percebido em discursos como fator conflitante. Considerando os relatos, compreendem-se duas situações: distanciamento conjugal e maior aproximação do casal.

Nos discursos das mães, foram pontuadas mudanças no comportamento paterno, que, embora na percepção da mãe não estavam relacionadas com a vinda de uma criança deficiente, posteriormente abordam sobre a expectativa frustrada de participação mais efetiva do pai da criança:

"A mesma coisa que era antes. Só que eu achava que ele ia tá (...) mais próximo e tá mais distante, entendeu? Agora eu num sei se é por causa que o menino nasceu com microcefalia ou porque ele é grosso em si [risos]" (mãe da CR001).

"Mudou por ele mesmo. Já tinha um tempo que ele tava diferente, mas por causa de [nome do filho] não. Achei que ele iria mudar, ficar mais presente, ser mais um pai realmente, quem nem deveria ser, mas por causa de [nome da criança], mudou nada não" (mãe da CR005).

Além disso, percebem-se no segmento do discurso da mãe de CR009 fatores que agravaram e acentuaram alguns aspectos do casal como pouca maturidade conjugal e sinais de desgastes no relacionamento: “...não foi pelo fato dele ter microcefalia não, porque até tava tranquilo antes de [nome] nascer, aí depois de [nome] eu fiquei mais estressada, mais impaciente, (...) mas não por ele ter microcefalia, mas por conta dos choros dele. Aí só aumentou. Daí em diante só gerou mais briga, mais briga (...) aí ele [esposo] começou a ficar também estressado...”.

Assim também, como fator contributivo da separação, captura-se no discurso a sobrecarga materna no cuidado com a criança nos primeiros meses, momento em que apresentava intensa irritabilidade. Essa característica é comumente encontrada entre crianças com SCZV 26. Mesmo que a mãe relate que a separação não se deveu à microcefalia, percebe-se na citação que o estresse materno por causa do choro frequente está associado ao maior número de brigas conjugais que culminaram na separação do casal.

Os discursos sobre a separação conjugal versus paternidade, na perspectiva materna, ainda que diante da separação, deveria ocorrer maior participação do pai na vida da criança. Todavia, isso não foi concretizado e, na concepção materna, a ausência está associada com a presença da deficiência. Como presente no trecho do discurso: “...eu acho que independente que eu esteja com ele ou não... ele tinha que dar atenção pro filho dele né. (...) já tem mais de cinco meses que ele [pai] viu ele [criança]. (...) Acho que tem preconceito, porque ele tem um filhinho [outro filho], e ele é super apegado com ele. Todo final de semana ele vai lá, pega, faz de tudo por ele [outro filho]. E por ele [filho com SCZV], não liga pra saber como é que ele tá, nunca ligou" (mãe da CR007).

A família sofre o impacto decorrente das mudanças no planejamento provocadas pela chegada de uma criança com deficiência, e atua de acordo com as ferramentas disponíveis. Consequentemente, repassa para os demais membros da rede social a interpretação da vivência de cuidado da criança com deficiência, com variação entre uma visão mais positiva ou não 13 .

Entretanto, alguns discursos relatam que o nascimento de uma criança com deficiência aproximou os cônjuges, deixando-os mais unidos no momento de adaptação familiar. Como pode ser visto no discurso do familiar da CR002, que se encontravam em situação de separação conjugal e a vinda de uma criança com deficiência aproximou-os, tornando-os mais companheiros: "mudou, mudou, a gente 
ficou mais carinhoso assim com o outro né, depois de [nome do filho], antes a gente já gostava um do outro, aí depois de [nome do filho] aumentou mais o sentimento [nome do filho] (...). Aproximou mais, mudou a minha vida, é um amor imenso".

Nesse aspecto, também foram observadas outras mudanças positivas relatadas pela mãe da CR006, que informam o pai estar mais presente no cotidiano da família e obteve melhorias no relacionamento conjugal pela mudança no comportamento individual provocada pelo nascimento da criança com deficiência: "melhorou mais [risos], antes ele saia muito, me deixava só, agora ele está mais presente, me ajuda a cuidar do menino, melhorou mais no comportamento dele (...) mudou muito".

Os aspectos positivos da relação conjugal demonstrados na pesquisa remetem à capacidade humana de enfrentamento das adversidades e oportunidade de aperfeiçoamento dos relacionamentos mediante uma situação de crise.

Segundo Silva \& Dessen 13, existe uma tendência entre estudos sobre famílias de crianças com deficiência em evidenciar as fragilidades em contraponto às "suas possibilidades adaptativas e saudáveis”. Juliano \& Yunes 27 destacam que o momento de crise na família também oportuniza para a capacidade de transcender a situação, provocando mudanças positivas pela capacidade de "resiliência" humana.

\section{Conclusão}

Finalmente, a pesquisa demonstra que para a maioria dos entrevistados, uma criança com diagnóstico de SCZV traz importantes mudanças na dinâmica familiar, como maior dependência da criança ao cuidador, que majoritariamente é do gênero feminino, aumento de gastos financeiros devido à necessidade de deslocamento para os serviços de saúde, além de absenteísmo no trabalho. Consequentemente, fortalecer a rede social dessas famílias é um importante fator a ser levado em consideração para que se garantam melhores condições de vida para as crianças e suas respectivas famílias.

Como fator limitante, tem-se o fato de se tratar de um estudo restrito aos cuidadores de crianças com SCZV residentes no Município de Petrolina, o que não permite conhecer na totalidade a realidade vivência pelas demais famílias em situação semelhante.

\section{Colaboradores}

S. A. A. G. Sá contribuiu com a concepção, planejamento, análise e interpretação dos dados, elaboração e revisão crítica do conteúdo e aprovou a versão final do manuscrito. C. C. Galindo, R. S. Dantas e J. C. Moura contribuíram com a revisão crítica do conteúdo e aprovaram a versão final do manuscrito.

\section{Agradecimentos}

À Secretaria Municipal de Saúde de Petrolina, aos servidores da UBS AME Amália Granja, em especial aos profissionais do Núcleo Ampliado de Saúde da Família (NASF), bem como todas as crianças e seus familiares pela colaboração e pela confiança, partilhando suas experiências.

\section{Informações adicionais}

ORCID: Simone Aline Araújo Guimarães de Sá (0000-0002-6413-5962); Claudia Cavalcanti Galindo (0000-0001-7495-303X); Regina Santos Dantas (0000-0002-8130-1459); José Carlos de Moura (0000-0001-6943-1560). 


\section{Referências}

1. Mendes A. Ministério da Saúde declara fim da emergência nacional para Zika. Notícias SVS 2017; 11 mai. http://www.saude.gov.br/noti cias/svs/28348-ministerio-da-saude-declarafim-da-emergencia-nacional-para-zika-e-mi crocefalia.

2. Aragao MFV, van der Linden V, Brainer-Lima AM, Coeli RR, Silva PS, van der Linden A, et al. Clinical features and neuroimaging (CT and MRI) findings in presumed Zika virus related congenital infection and microcephaly: retrospective case series study. BMJ 2016; 353:11901.

3. Secretaria Executiva de Vigilância em Saúde, Secretaria Estadual de Saúde de Pernambuco. Síndrome congênita relacionada à infecção pelo vírus Zika. Informe técnico 23/2017. Recife: Secretaria Estadual de Saúde de Pernambuco; 2017.

4. Ministério da Saúde. Registro de casos de microcefalia e/ou alteração do sistema nervoso central (SC). Brasília: Ministério da Saúde; 2017.

5. World Health Organization. WHO statement on the first meeting of the International Health Regulations (2005) (IHR 2005) Emergency Committee on Zika virus and observed increase in neurological disorders and neonatal malformations. http://www.who.int/media centre/news/statements/2016/1st-emer gency-committee-zika/en/ (acessado em 23/ Nov/2016).

6. Ashwal S, Michelson D, Plawner L, Dobyns WB; Quality Standards Subcommittee of the American Academy of Neurology and the Practice Committee of the Child Neurology Society. Practice parameter: evaluation of the child with microcephaly (an evidence-based review): report of the Quality Standards Subcommittee of the American Academy of Neurology and the Practice Committee of the Child Neurology Society. Neurology 2009; 73:887-97.

7. Centers for Disease Control and Prevention. CDC issues guidelines for Zika virus in pregnancy CME/CE. http://www.sbp.com.br/src/ uploads/2016/02/CDC-Issues-Guidelinesfor-Zika-Virus-in-Pregnancy_Medscap.pdf (acessado em 20/Nov/2017).

8. Mlakar J, Korva M, Tul N, Popović M, PoljšakPrijatelj M, Mraz J, et al. Zika virus associated with microcephaly. N Engl J Med 2016; 374:951-8.

9. Cragan JD, Mai CT, Petersen EE, Liberman RF, Forestieri NE, Stevens AC, et al. Baseline prevalence of birth defects associated with congenital Zika virus infection - Massachusetts, North Carolina, and Atlanta, Georgia, 2013-2014. MMWR Morb Mortal Wkly Rep 2017; 66:219-22.

10. Silva SC, Dessen MA. Deficiência mental e família: implicações para o desenvolvimento da criança. Psicol Teor Pesqui 2001; 17:133-41.
11. Franco V, Apolónio AM. Desenvolvimento, resiliência e necessidades das famílias de crianças com deficiência. Ciencia Psicológica 2002; (8):40-54.

12. Flamenghi Jr. GA, Messa AA. Pais, filhos e deficiência: estudos sobre as relações familiares. Psicol Ciênc Prof 2007; 27:236-45.

13. Silva SC, Dessen MA. Relações familiares na perspectiva de pais, irmãos e crianças com deficiências. Rev Bras Educ Espec 2014; 20:421-34.

14. Conselho Nacional de Saúde. Resolução no 466, de 12 de dezembro de 2012. Aprova diretrizes e normas regulamentadoras de pesquisas envolvendo seres humanos. Diário Oficial da União 2013; 13 jun.

15. Bardin L. Análise de conteúdo. São Paulo: Edições 70; 2016.

16. Turato ER. Qualitative and quantitative methods in health: definitions, differences and research subjects. Rev Saúde Pública 2005; 39:507-14

17. Viana ALA, coordenadora. Pesquisa política, planejamento e gestão das regiões e redes de atenção à saúde no Brasil. http://www.resbr. net.br/wp-content/uploads/2017/06/dossie_ petrolina_juazeiro_dossie_completo.pdf (acessado em 21/Nov/2017).

18. Departamento de Informática do SUS. Cadastro Nacional de Estabelecimentos de Saúde. Brasília: Ministério da Saúde; 2016.

19. Minayo MCS. O desafio do conhecimento. São Paulo: Editora Hucitec; 2007.

20. Silva CR, Gobbi BC, Simão AA. O uso da análise de conteúdo como uma ferramenta para a pesquisa qualitativa: descrição e aplicação do método. Organizações Rurais \& Agroindustriais 2005; 7:70-81.

21. Carneiro RG. Zika, uma agenda de pesquisa para (o pensar) nas ciências sociais e humanas em saúde. Interface (Botucatu) 2017; 21:753-7.

22. Marinho F, Araújo VEM, Porto DL, Ferreira HL, Coelho MRS, Lecca RCR, et al. Microcefalia no Brasil: prevalência e caracterização dos casos a partir do Sistema de Informações sobre Nascidos Vivos (Sinasc), 2000-2015. Epidemiol Serv Saúde 2016; 25:701-12.

23. Scott RP, Quadros MT, Rodrigues AC, Lira LC, Matos SS, Meira F, et al. A epidemia de Zika e as articulações das mães num campo tensionado entre feminismo, deficiência e cuidados. Cadernos de Gênero e Diversidade 2017; 3:73-92.

24. Williamson KE. Cuidado nos tempos de Zika: notas da pós-epidemia em Salvador (Bahia), Brasil. Interface (Botucatu) 2018; 22:685-96.

25. Diniz D. Vírus zika e mulheres. Cad Saúde Pública 2016; 32:e0046316.

26. Secretaria de Vigilância em Saúde, Ministério da Saúde. Monitoramento integrado de alterações no crescimento e desenvolvimento relacionadas à infecção pelo vírus Zika e outras etiologias infecciosas, até a semana epidemiológica 28/2017. Boletim Epidemiológico 2017; 48(24). 
27. Juliano MC, Yunes MAM. Reflexões sobre rede de apoio social como mecanismo de proteção e promoção de resiliência. Ambiente e Sociedade 2014; 17:135-54.

28. Departamento de Ações Programáticas Estratégicas, Secretaria de Atenção à Saúde, Ministério da Saúde. Diretrizes de atenção à pessoa com paralisia cerebral. Brasília: Ministério da Saúde; 2013.

\section{Abstract}

Brazil witnessed a significant increase in the number of cases of microcephaly in infants born in the second semester of 2015. There were 162 cases in 2014, increasing to 1,608 in 2015. The condition is associated with impairments in various bodily functions, leading to limitations in infant development. This study aims to analyze the family $d y$ namics of children with congenital Zika syndrome (CZS) in Petrolina, Pernambuco State. Data collection used consultation in patient charts and interviews with parents using a semi-structured script. A qualitative/quantitative approach was used, including all of the mothers and other family members accompanying children with CZS at the referral unit, the Amália Granja Alencar Clinic. Discourse analysis applied the content analysis technique. The results in the category "changes in daily living" for families of children with CZS were grouped into three subcategories: activities of daily living $(A D L)$, financial and occupational impacts associated with the CZS diagnosis, and changes in the marital relationship after the diagnosis. The study showed that care for the child with CZS is mostly concentrated in women in the family, and that the diagnosis leads to significant changes in the family dynamics, with the child's extensive dependence on the caregiver, increasing expenses, and work absenteeism.

Microcephaly; Disabled Children; Health Centers; Zika Virus; Family Relations
29. Secretaria de Atenção à Saúde, Ministério da Saúde. Protocolo de atenção à saúde e resposta à ocorrência de microcefalia relacionada à infecção pelo vírus zika. Brasília: Ministério da Saúde; 2016.

30. Vernier ETN, Cabral IE. Caracterização de crianças com necessidades especiais e de saúde e seus familiares cuidadores. Santa Maria (RS) 2004-2005. Subsídios para a intervenção de enfermagem. Rev Soc Bras Enferm Pediatras 2006; 6:37-45.

\section{Resumen}

En Brasil, se produjo un aumento en el número de casos de microcefalia detectada en niños nacidos en el segundo semestre de 2015. Estos casos sufrieron un incremento significativo en el país. En 2014, fueron 162 incidencias, aumentando, en 2015, hasta 1.608. Esta enfermedad está asociada con varias alteraciones en las funciones del organismo, provocando limitaciones en el desarrollo infantil. El objetivo de esta investigación fue analizar la dinámica familiar de niños con el síndrome congénito asociado al virus Zika (SCZ) en el municipio de Petrolina, Pernambuco. Como instrumento de recogida, se realizaron consultas del historial clínico, así como una entrevista semiestructurada. Se empleó un abordaje cuali-cuantitativo, implicando a la totalidad de las madres y de los familiares que acompañaban a los niños con el SCZ en la unidad de salud de referencia, AME Amália Granja Alencar. En el análisis de los discursos se aplicó la técnica de análisis de contenido. Los resultados relacionados con la categoría cambios de la vida diaria de familiares del niño con el SCZ se agruparon en tres subcategorias: actividad de la vida diaria (AVD), impactos financieros $y$ en el trabajo asociados al descubrimiento del SCZ y cambios en la relación conyugal tras el descubrimiento del SCZ. La investigación demostró que mayoritariamente el cuidado del niño con SCZ está centrado en la figura femenina, y que el diagnóstico conlleva significativos cambios en la dinámica familiar, como una mayor dependencia del niño del cuidador, aumento de gastos financieros y absentismo en el trabajo.

Microcefalia; Niños con Discapacidad; Centros de Salud; Virus Zika; Relaciones Familiares

Recebido em 19/Dez/2018

Versão final reapresentada em 06/Ago/2019

Aprovado em 23/Ago/2019 